\title{
Molecular imaging of hypoxia with radiolabelled agents
}

\author{
Gilles Mees • Rudi Dierckx • Christel Vangestel • \\ Christophe Van de Wiele
}

Received: 4 February 2009 / Accepted: 7 June 2009/Published online: 30 June 2009

(C) The Author(s) 2009. This article is published with open access at Springerlink.com

\begin{abstract}
Tissue hypoxia results from an inadequate supply of oxygen $\left(\mathrm{O}_{2}\right)$ that compromises biological functions. Structural and functional abnormalities of the tumour vasculature together with altered diffusion conditions inside the tumour seem to be the main causes of tumour hypoxia. Evidence from experimental and clinical studies points to a role for tumour hypoxia in tumour propagation, resistance to therapy and malignant progression. This has led to the development of assays for the detection of hypoxia in patients in order to predict outcome and identify patients with a worse prognosis and/or patients that would benefit from appropriate treatments. A variety of invasive and noninvasive approaches have been developed to measure tumour oxygenation including oxygen-sensitive electrodes and hypoxia marker techniques using various labels that can be detected by different methods such as positron emission tomography (PET), single photon emission com-
\end{abstract}

\footnotetext{
G. Mees $\cdot$ R. Dierckx $\cdot$ C. Van de Wiele

Department of Nuclear Medicine and Molecular Imaging, University Medical Center Groningen, University of Groningen, Groningen, The Netherlands

R. Dierckx $\cdot$ C. Van de Wiele

Department of Nuclear Medicine,

University Hospital Ghent,

Ghent, Belgium

C. Vangestel

Department of Gastroenterology, University Hospital Ghent,

Ghent, Belgium

C. Van de Wiele $(\square)$

Department of Nuclear Medicine, University Hospital Ghent, De Pintelaan 185 , 9000 Ghent, Belgium

e-mail: christophe.vandewiele@ugent.be
}

puted tomography (SPECT), magnetic resonance imaging (MRI), autoradiography and immunohistochemistry. This review aims to give a detailed overview of non-invasive molecular imaging modalities with radiolabelled PET and SPECT tracers that are available to measure tumour hypoxia.

Keywords Hypoxia $\cdot$ PET $\cdot$ SPECT $\cdot$ Nitroimidazole

\section{Hypoxia in tumour biology}

The prevalence of hypoxic areas is a characteristic feature of locally advanced solid tumours and has been described in a wide range of human malignancies, including cancer of the breast, uterine cervix, vulva, head and neck, prostate, rectum, pancreas as well as in brain tumours, soft tissue sarcomas and malignant melanomas. Up to $50-60 \%$ of locally advanced solid tumours may exhibit hypoxic and/or anoxic tissue areas that are heterogeneously distributed within the tumour mass. These hypoxic areas result from an imbalance between oxygen supply and consumption which is caused by abnormal structure and function of the microvessels supplying the tumour (causing acute hypoxia), increased diffusion distances between the nutritive blood vessels and the tumour cells (causing chronic hypoxia), and reduced $\mathrm{O}_{2}$ transport capacity of the blood due to the presence of disease- or treatment-related anaemia [1-3]. Recent studies have demonstrated a clear relevance of this hypoxic microenvironment to tumour-associated metabolic alterations, which are tightly linked to the biology of the tumour. In this respect, tumour hypoxia has been associated with an aggressive tumour phenotype, poor response to radiotherapy and chemotherapy, increased risk of invasion and metastasis, and worse prognosis in advanced squamous 
cell carcinoma of the cervix $[4,5]$, head and neck [6-8], and soft-tissue sarcomas [9].

Many of the adaptations to tumour hypoxia seem to be orchestrated by the transcription factor hypoxia-inducible factor (HIF)-1, which has been verified as a master regulator of oxygen homeostasis under hypoxic conditions. Its oxygen-dependent activity is regulated in a delicate interplay between several factors in which a family of prolyl hydroxylase domain-containing proteins or PHDs 13, the von Hippel-Lindau (VHL) tumour suppressor protein (pVHL) and an E3 ubiquitin ligase complex, amongst many others, play an important role. The HIF-1 pathway mediates critical hypoxic adaptations by the induction of target genes involved in glucose metabolism, angiogenesis, erythropoiesis and apoptosis. These target genes include vascular endothelial growth factor (VEGF), facilitative glucose transporters (GLUTs), hexokinases (HKs), erythropoietin (EPO), carbonic anhydrase IX (CAIX), ... The resulting adaptive changes in the proteome and genome of the tumour cells are believed to lead to more aggressive clones which are better adapted to survive in their compromised situation. Subsequent selection and clonal expansion of these clones lead to a more adapted and aggressive tumour cell population [1-3]. As noted above, the presence of tumour hypoxia appears to impair the effectiveness of common anticancer therapies like radiotherapy (RT) and chemotherapy. Hypoxia-induced radioresistance is multifactorial. Besides the above-mentioned proteomic and genomic changes that most likely contribute to resistance by increasing the number of mutated cells that are more resistant to apoptosis and by causing upregulation of several stress proteins, the main reason for radioresistance is the intrinsic dependence of RT on oxygen to cause damage to the tumour cell. For damage to be inflicted on tumour cells by ionizing radiation, the presence of oxygen is necessary because it mediates DNA damage through formation of free radicals by interaction of ionizing radiation with intracellular water. Hypoxia has also been shown to reduce chemotherapeutic efficacy by causing cells within hypoxic regions to cycle more slowly and by providing a selection mechanism for cells with reduced susceptibility for apoptosis. Additionally, due to limited drug penetration within solid tumours, hypoxic regions are often protected from the cytotoxic effects of chemotherapeutic agents further reducing drug efficacy [1-3].

All these mechanisms together ensure that tumour hypoxia is a negative prognostic factor. In order to predict outcome and identify patients with a worse prognosis and/ or patients that would benefit from appropriate treatments, in vivo measurement of tumour hypoxia is required. At present, the gold standard for direct in vivo determination of tumour oxygenation is a commercially available oxygen electrode, commonly referred to as the Eppendorf electrode.
As mentioned above, tumour oxygenation measurements obtained with this technique correlated well with clinical outcome in several clinical trials [4-9]. However, this technically demanding procedure has a number of drawbacks and limitations like its sensitivity for sampling errors, its invasive nature and the fact that only easily accessible tumours can be studied. Therefore, the search for a noninvasive assay for tumour hypoxia continues. Non-invasive measurement of tumour hypoxia with PET and SPECT will be discussed below.

\section{Non-invasive measurement of tumour hypoxia with PET}

\section{Nitroimidazole compounds}

These compounds are reduced into reactive intermediary metabolites by intracellular reductases in a process which is directly related to the level of oxygenation/hypoxia. This causes a gradient which is favourable for detection of hypoxic cells. Subsequently, these metabolites covalently bind to thiol groups of intracellular proteins and thereby accumulate within viable hypoxic cells. When labelled with a PET tracer, these chemicals can be detected using PET imaging methods. Several nitroimidazole compounds with different properties and labelled with different PET radionuclides have been described $[10,11]$.

\section{(a) $\left[{ }^{18} \mathrm{~F}\right]$ FMISO $\left(\left[{ }^{18} \mathrm{~F}\right]\right.$ fluoromisonidazole $)$}

Pre-clinical data: Kubota et al. evaluated the tumour imaging potential of $\left[{ }^{18} \mathrm{~F}\right] \mathrm{FMISO}$ in an AH109A tumour rat xenograft and examined the correlation between intratumoural distributions of $\left[{ }^{18} \mathrm{~F}\right] \mathrm{FMISO},{ }^{14} \mathrm{C}$-2-deoxyglucose and ${ }^{14} \mathrm{C}$-methionine. Hypoxic and radioresistant tumours could be identified by increased $\left[{ }^{18} \mathrm{~F}\right]$ FMISO uptake. A large overlap in the distribution of $\left[{ }^{18} \mathrm{~F}\right] \mathrm{FMISO}$ and ${ }^{14} \mathrm{C}-2$ deoxyglucose and a small overlap in the distribution of $\left[{ }^{18} \mathrm{~F}\right]$ FMISO and ${ }^{14} \mathrm{C}$-methionine were observed [12]. In a study by Rasey et al., an attempt was made to define the relationship between $\left[{ }^{18} \mathrm{~F}\right] \mathrm{FMISO}$ uptake and radiobiologically hypoxic fraction in a 36B10 glioma rat xenograft. Although the relationship between classically defined radiobiologically hypoxic fraction and $\left[{ }^{18} \mathrm{~F}\right] \mathrm{FMISO}$ timeactivity data remained to be clarified, $\left[{ }^{18} \mathrm{~F}\right] \mathrm{FMISO}$ retention provided useful correlations with the degree of hypoxia [13]. Bentzen et al. compared $\left[{ }^{18} \mathrm{~F}\right] \mathrm{FMISO}$ uptake with invasive Eppendorf electrode $\mathrm{pO}_{2}$ measurements in a $\mathrm{C} 3 \mathrm{H}$ mammary carcinoma mouse xenograft and found no direct correlation between both methods [14].

A number of studies compared $\left[{ }^{18} \mathrm{~F}\right] \mathrm{FMISO}$ uptake with immunohistochemical staining techniques. In a study by Dubois et al., $\left[{ }^{18} \mathrm{~F}\right] \mathrm{FMISO}$ uptake was compared with the 
exogenous hypoxia marker pimonidazole and the endogenous hypoxia marker carbonic anhydrase IX (CA IX) in a rhabdomyosarcoma rat xenograft. A statistically significant correlation was obtained between the hypoxic volumes defined with $\left[{ }^{18} \mathrm{~F}\right]$ FMISO PET and the volumes derived from the pimonidazole- and CA IX-stained tumour sections, indicating the value of $\left[{ }^{18} \mathrm{~F}\right] \mathrm{FMISO}$ PET to measure hypoxia [15]. Troost et al. tried to validate $\left[{ }^{18} \mathrm{~F}\right]$ FMISO PET by comparing $\left[{ }^{18} \mathrm{~F}\right] \mathrm{FMISO}$ uptake with pimonidazole staining in several xenograft models in two different studies. Both studies found a correlation between $\left[{ }^{18} \mathrm{~F}\right] \mathrm{FMISO}$ uptake and pimonidazole immunohistochemistry $[16,17]$.

In a number of studies, $\left[{ }^{18} \mathrm{~F}\right] \mathrm{FMISO}$ uptake was compared with $\left[{ }^{18} \mathrm{~F}\right] \mathrm{FDG}$ uptake. Most of these studies demonstrated the feasibility and utility of $\left[{ }^{18} \mathrm{~F}\right]$ FMISO PET imaging to identify tumour hypoxia, whereas $\left[{ }^{18} \mathrm{~F}\right] \mathrm{FDG}$ PET imaging seemed less suitable for this purpose [18-22].

Clinical data: Valk et al. were the first to demonstrate the feasibility of $\left[{ }^{18} \mathrm{~F}\right] \mathrm{FMISO}$ PET to detect tumour hypoxia in three patients with malignant glioma [23]. Rasey et al. assessed pre-treatment hypoxia in a variety of human tumours using $\left[{ }^{18} \mathrm{~F}\right] \mathrm{FMISO}$ PET and concluded that human tumour hypoxia is widely prevalent and highly variable between different tumours with the same histology and also between regions within the same tumour [24]. In a study by Bruehlmeier et al. where hypoxia was measured in 11 patients with various brain tumours, it was concluded that late $\left[{ }^{18} \mathrm{~F}\right] \mathrm{FMISO}$ PET images provide a spatial description of tumour hypoxia which may develop irrespective of the magnitude of perfusion as measured with ${ }^{15} \mathrm{O}-\mathrm{H}_{2} \mathrm{O}$ PET [25].

A number of studies compared $\left[{ }^{18} \mathrm{~F}\right] \mathrm{FMISO}$ uptake with invasive Eppendorf electrode $\mathrm{pO}_{2}$ measurements. In some of these studies, $\left[{ }^{18} \mathrm{~F}\right] \mathrm{FMISO}$ uptake in renal cell carcinoma and head and neck cancer correlated well with $\mathrm{pO}_{2}$ measurements from polarographic needle oxygen electrodes, confirming the use of $\left[{ }^{18} \mathrm{~F}\right]$ FMISO PET to measure tumour hypoxia [26-29]. Bentzen et al., however, found no correlation between $\left[{ }^{18} \mathrm{~F}\right] \mathrm{FMISO}$ uptake and $\mathrm{pO}_{2}$ measurements in human soft tissue tumours [30]. Some of the above-mentioned studies also compared uptake of $\left[{ }^{18} \mathrm{~F}\right]$ FDG and $\left[{ }^{18} \mathrm{~F}\right] \mathrm{FMISO}$ in patients with head and neck cancer. They found no correlation between $\left[{ }^{18} \mathrm{~F}\right] \mathrm{FDG}$ uptake and $\mathrm{pO}_{2}$ measurements, whereas an association between $\left[{ }^{18} \mathrm{~F}\right] \mathrm{FMISO}$ uptake and $\mathrm{pO}_{2}$ measurements existed [27-29]. Further comparison of $\left[{ }^{18} \mathrm{~F}\right] \mathrm{FDG}$ and $\left[{ }^{18} \mathrm{~F}\right] \mathrm{FMISO}$ indicated that no correlation exists between both tracers as both represent different tumour characteristics [31-35].

Several clinical studies have used $\left[{ }^{18} \mathrm{~F}\right]$ FMISO PET as a prognostic indicator in oncology. In a study by Rajendran et al., the prognostic effect of pre-therapy $\left[{ }^{18} \mathrm{~F}\right]$ FMISO PET on survival was investigated in 73 patients with head and neck cancer, and pre-treatment $\left[{ }^{18} \mathrm{~F}\right] \mathrm{FMISO}$ uptake proved to be an independent prognostic factor [36]. Another study of 12 patients with head and neck carcinoma who received a pre-radiotherapy $\left[{ }^{18} \mathrm{~F}\right] \mathrm{FMISO}$ PET scan concluded that $\left[{ }^{18} \mathrm{~F}\right]$ FMISO uptake was predictive of treatment response to radiotherapy [35]. Similarly, in 40 patients with advanced head and neck cancer and non-small cell lung cancer, outcome after radiotherapy could be predicted on the basis of kinetic behaviour of $\left[{ }^{18} \mathrm{~F}\right] \mathrm{FMISO}$ in tumour tissue [37]. Two studies investigating the prognostic significance of $\left[{ }^{18} \mathrm{~F}\right]$ FMISO PET in patients with head and neck cancer receiving chemoradiation in combination with the hypoxia sensitizer tirapazamine concluded that $\left[{ }^{18} \mathrm{~F}\right] \mathrm{FMISO}$ uptake can predict prognosis and is associated with a high risk of locoregional failure $[38,39]$. Cher et al. showed that in patients with malignant glioma $\left[{ }^{18} \mathrm{~F}\right] \mathrm{FMISO}$ uptake is prognostic for treatment outcome in the majority of patients [34]. In a study with eight patients with non-small cell lung cancer receiving chemotherapy and/or radiotherapy, changes in $\left[{ }^{18} \mathrm{~F}\right] \mathrm{FMISO}$ uptake measured early response to therapy and may predict freedom from disease as well as overall survival [40]. A recent study that was conducted to evaluate the reproducibility of $\left[{ }^{18} \mathrm{~F}\right] \mathrm{FMISO}$ intratumour distribution in 20 patients with head and neck cancer showed considerable variability in the intratumour uptake that can occur between repeated $\left[{ }^{18}\right.$ F]FMISO PET scans performed 3 days apart [41].

\section{(b) $\left[{ }^{18} \mathrm{~F}\right] \mathrm{FAZA}\left(\left[{ }^{18} \mathrm{~F}\right]\right.$ fluoroazomycin-arabinofuranoside)}

Pre-clinical data: Sorger et al. compared the selective uptake of $\left[{ }^{18} \mathrm{~F}\right] \mathrm{FMISO}$ and $\left[{ }^{18} \mathrm{~F}\right] \mathrm{FAZA}$ in hypoxic cells in vitro and in a Walker 256 rat sarcoma model. The in vitro study showed that $\left[{ }^{18} \mathrm{~F}\right] \mathrm{FAZA}$ is able to indicate reduced oxygen supply in the same order of magnitude of $\left[{ }^{18} \mathrm{~F}\right]$ FMISO. The in vivo study, however, indicated that $\left[{ }^{18} \mathrm{~F}\right]$ FMISO displayed a slightly higher standardized uptake value and tumour to muscle ratio compared to $\left[{ }^{18} \mathrm{~F}\right] \mathrm{FAZA}$ though the elimination of the latter was much faster [42]. Two other studies also compared $\left[{ }^{18} \mathrm{~F}\right] \mathrm{FMISO}$ and $\left[{ }^{18} \mathrm{~F}\right]$ FAZA in various tumour mice xenografts and reported superior biokinetics for $\left[{ }^{18} \mathrm{~F}\right] \mathrm{FAZA}$ compared with $\left[{ }^{18} \mathrm{~F}\right]$ FMISO. In both studies $\left[{ }^{18} \mathrm{~F}\right]$ FAZA displayed higher tumour to background, tumour to muscle and tumour to blood ratios due to its more rapid clearance from blood and non-target tissues [43, 44]. Beck et al. evaluated the predictive value of $\left[{ }^{18} \mathrm{~F}\right] \mathrm{FAZA}$ PET for success of radiotherapy in combination with tirapazamine in EMT6 tumour mice xenografts. High $\left[{ }^{18}\right.$ F]FAZA uptake was identified as an independent adverse prognostic factor for tumour progression, and hypoxia imaging with $\left[{ }^{18} \mathrm{~F}\right] \mathrm{FAZA}$ PET was able to predict the success of radiochemotherapy [45]. In a study by Busk et al., $\left[{ }^{18}\right.$ F]FAZA uptake was 
compared with Eppendorf electrode measurements and the hypoxia marker pimonidazole. The distribution of $\left[{ }^{18} \mathrm{~F}\right]$ FAZA proved to be consistent with tumour hypoxia, as identified with the Eppendorf electrode measurements and the hypoxia marker pimonidazole [46]. The same group compared the in vitro hypoxia specificity of cellular $\left[{ }^{18} \mathrm{~F}\right]$ FDG and $\left[{ }^{18} \mathrm{~F}\right]$ FAZA retention and tested tracer distribution between hypoxic and non-hypoxic areas in different mice xenografts. The in vitro as well as the in vivo experiments indicated that $\left[{ }^{18} \mathrm{~F}\right] \mathrm{FAZA}$ is an excellent marker for tumour hypoxia, whereas $\left[{ }^{18} \mathrm{~F}\right] \mathrm{FDG}$ is not [47].

Clinical data: Souvatzoglou et al. evaluated the feasibility of $\left[{ }^{18} \mathrm{~F}\right] \mathrm{FAZA}$ PET for the imaging of tumour hypoxia in 11 patients with head and neck cancer and concluded that PET imaging with $\left[{ }^{18} \mathrm{~F}\right] \mathrm{FAZA}$ is feasible and that adequate image quality is achieved [48]. Another study, which included 18 patients with advanced squamous cell head and neck cancer, evaluated the role of $\left[{ }^{18} \mathrm{~F}\right]$ FAZA PET imaging to identify hypoxia in order to plan radiation treatment. It was concluded that radiation treatment planning and intensity-modulated radiotherapy based on $\left[{ }^{18}\right.$ F]FAZA uptake measurements are feasible [49].

\section{(c) $\left[{ }^{18}\right.$ F]FETA $\left(\left[{ }^{18}\right.\right.$ F $]$ fluoroetanidazole)}

In a study by Rasey et al., four cultured rodent cell lines were incubated with $\left[{ }^{18} \mathrm{~F}\right]$ FETA for various times under graded $\mathrm{O}_{2}$ concentrations. The biodistributions of $\left[{ }^{18} \mathrm{~F}\right]$ FETA and $\left[{ }^{18} \mathrm{~F}\right]$ fluoromisonidazole (FMISO) at 2 and $4 \mathrm{~h}$ post-injection in $\mathrm{C} 3 \mathrm{H}$ mice bearing KHTn tumours were also compared. $\left[{ }^{18} \mathrm{~F}\right]$ FMISO and $\left[{ }^{18} \mathrm{~F}\right]$ FETA demonstrated similar oxygen dependency of binding in cultured cells. However, differences in biodistribution suggested advantages of $\left[{ }^{18} \mathrm{~F}\right]$ FETA over $\left[{ }^{18} \mathrm{~F}\right]$ FMISO because $\left[{ }^{18} \mathrm{~F}\right]$ FETA appeared to be less metabolized in vivo than $\left[{ }^{18} \mathrm{~F}\right] \mathrm{FMISO}$ [50]. In another study, the cellular transport and retention of $\left[{ }^{18} \mathrm{~F}\right]$ FETA were determined in vitro under air and nitrogen and the biodistribution and metabolism were determined in mice bearing several different xenografts. It was concluded that $\left[{ }^{18} \mathrm{~F}\right]$ FETA has suitable physicochemical properties and is stable to non-hypoxic degradation in vivo. It was also demonstrated that the tumour retention of the radiotracer is related to radiobiological hypoxia and $\mathrm{pO}_{2}$ status as determined with polarographic needle oxygen electrodes [51].

\section{(d) $\left[{ }^{18} \mathrm{~F}\right]$ FETNIM $\left(\left[{ }^{18} \mathrm{~F}\right]\right.$ fluoroerythronitroimidazole $)$}

Pre-clinical data: Yang et al. reported on the synthesis and evaluation of $\left[{ }^{18} \mathrm{~F}\right]$ FETNIM. Their results indicated that at $4 \mathrm{~h}$ after injection, tumour to blood and tumour to muscle ratios in mammary tumour-bearing rats were significantly higher with $\left[{ }^{18}\right.$ F]FETNIM than with $\left[{ }^{18}\right.$ F]FMISO [52]. In a later study by Grönroos et al. where the pharmacokinetic properties and metabolite formation of $\left[{ }^{18} \mathrm{~F}\right] \mathrm{FETNIM}$ were studied, $\left[{ }^{18} \mathrm{~F}\right]$ FETNIM showed low peripheral metabolism, little defluorination and possible metabolic trapping in hypoxic tumour tissue [53]. In a pre-clinical study by the same group, the hypoxia imaging ability of $\left[{ }^{18} \mathrm{~F}\right]$ FETNIM was compared with that of $\left[{ }^{18} \mathrm{~F}\right] \mathrm{FMISO}$ in a $\mathrm{C} 3 \mathrm{H}$ mammary carcinoma mice xenograft under different oxygenation conditions. Additionally, the biodistribution of both markers in normal tissues was assessed under similar conditions. Uptake of both tracers correlated with the oxygenation status in the tumours, but $\left[{ }^{18}\right.$ F]FETNIM showed a low and favourable background signal in normal tissues as compared with $\left[{ }^{18} \mathrm{~F}\right] \mathrm{FMISO}$ [54].

Clinical data: Most of the clinical studies with $\left[{ }^{18} \mathrm{~F}\right]$ FETNIM were performed in patients with head and neck cancer. A study investigating the accurate radiation dosimetry in 27 patients with head and neck cancer concluded that the effective dose of $\left[{ }^{18} \mathrm{~F}\right]$ FETNIM PET is well within the range of several related nuclear medicine procedures [55]. A lot of clinical studies were performed by researchers at the University of Turku in Finland. They found that $\left[{ }^{18} \mathrm{~F}\right]$ FETNIM uptake in the early phase of tissue accumulation, as measured using $\left[{ }^{15} \mathrm{O}\right] \mathrm{H}_{2} \mathrm{O}$ and $\mathrm{PET}$, was highly variable and depended for the most part on perfusion [56]. Tumour to plasma ratio provided the best estimate for tumour hypoxia [57]. In another study, the radiotherapy response was assessed by hypoxia imaging with $\left[{ }^{18}\right.$ F]FETNIM PET in 21 patients with head and neck cancer and high uptake of $\left[{ }^{18} \mathrm{~F}\right]$ FETNIM prior to radiation therapy was associated with a trend towards poor overall survival [58].

\section{(e) $\left[{ }^{18} \mathrm{~F}\right] \mathrm{EF} 5$}

In a study by Ziemer et al., the biodistribution of $\left[{ }^{18} \mathrm{~F}\right]$ EF5 was assessed using hepatoma and glioma rodent tumour models. $\left[{ }^{18} \mathrm{~F}\right] \mathrm{EF} 5$ was rapidly and uniformly distributed to all tissues. This together with its high drug stability in vivo suggests that $\left[{ }^{18} \mathrm{~F}\right] \mathrm{EF} 5$ is a promising agent for the non-invasive assessment of tumour hypoxia [59]. Another study investigated hypoxia in androgen-dependent, androgen-independent and regressing Shionogi tumours using $\left[{ }^{18} \mathrm{~F}\right] \mathrm{EF} 5$. Differences in hypoxia between the different types of tumours could be detected with $\left[{ }^{18} \mathrm{~F}\right]$ EF5 [60]. Recently, the first human study with $\left[{ }^{18} \mathrm{~F}\right] \mathrm{EF} 5$ was performed in 15 patients with squamous cell carcinoma of the head and neck (HNSCC) in which the time course of $\left[{ }^{18} \mathrm{~F}\right] \mathrm{EF} 5$ uptake after intravenous injection was evaluated to determine the most suitable PET protocol [61].

\section{(f) $\left[{ }^{18} \mathrm{~F}\right] \mathrm{EF} 3$}

Pre-clinical data: In the framework of the pre-clinical evaluation, Mahy et al. studied the pharmacokinetics, biodistribution, metabolism and specificity for hypoxia of $\left[{ }^{18} \mathrm{~F}\right] \mathrm{EF} 3$ in different tumour-bearing $\mathrm{C} 3 \mathrm{H}$ mice breathing carbogen $\left(5 \% \mathrm{CO}_{2}, 95 \% \mathrm{O}_{2}\right), 21 \%$ oxygen and $10 \%$ 
oxygen. They also compared $\left[{ }^{18} \mathrm{~F}\right] \mathrm{EF} 3$ uptake and EF5 adducts detected by immunofluorescence in the same model. $\left[{ }^{18} \mathrm{~F}\right] \mathrm{EF} 3$ uptake was inversely correlated with oxygen concentration, and a significant correlation was found between the $\left[{ }^{18} \mathrm{~F}\right] \mathrm{EF} 3$ tumour to muscle ratio and the fluorescence intensity of EF5 [62, 63]. Pharmacokinetics, biodistribution and metabolism of $\left[{ }^{18} \mathrm{~F}\right] \mathrm{EF} 3$ were assessed and compared with $\left[{ }^{18} \mathrm{~F}\right] \mathrm{FMISO}$ uptake in rodent tumour models. It was concluded that both exhibited similar pharmacokinetics, biodistribution and metabolism and that $\left[{ }^{18} \mathrm{~F}\right] \mathrm{FMISO}$ was able to detect tumour hypoxia to a similar extent as $\left[{ }^{18} \mathrm{~F}\right] \mathrm{EF} 3$, although it seemed less specific than the latter tracer [64]. The same group tried to increase the tumour to noise ratio in $\mathrm{C} 3 \mathrm{H}$ mice by increasing $\left[{ }^{18} \mathrm{~F}\right] \mathrm{EF} 3$ elimination. Several chemicals increasing renal filtration rate, decreasing tubular reabsorption or stimulating gastrointestinal elimination were tested. Only phenobarbital induced a trend toward an increase in tumour to noise ratio [65]. In another study, $\left[{ }^{18} \mathrm{~F}\right] \mathrm{EF} 3$ was quantitatively compared with $\left[{ }^{18} \mathrm{~F}\right] \mathrm{FMISO}$ in rats bearing syngeneic rhabdomyosarcoma tumours. It was shown that $\left[{ }^{18} \mathrm{~F}\right] \mathrm{EF} 3$ is cleared faster from the blood compared to $\left[{ }^{18} \mathrm{~F}\right] \mathrm{FMISO}$. Both had a similar tumour uptake at $4 \mathrm{~h}$ post-injection, a similarly fast and uniform distribution in normal tissues and a comparable intratumoural distribution, indicating that $\left[{ }^{18} \mathrm{~F}\right] \mathrm{EF} 3$ is not superior to $\left[{ }^{18} \mathrm{~F}\right] \mathrm{FMISO}[66]$.

Clinical data: In a recent phase I study by Mahy et al., pharmacokinetics, biodistribution and metabolism of $\left[{ }^{18} \mathrm{~F}\right]$ EF3 were assessed in ten patients with head and neck squamous cell carcinoma. Administration of $\left[{ }^{18} \mathrm{~F}\right] \mathrm{EF} 3$ seemed feasible and safe in head and neck cancer patients. Uptake and retention of the tracer was observed in the tumour, indicating the presence of hypoxia [67].

\section{(g) $\left[{ }^{18} \mathrm{~F}\right] \mathrm{EF} 1$}

Imaging with this marker was studied in two rat tumour types whereby the drug's biodistribution was assessed and optimized. $\left[{ }^{18} \mathrm{~F}\right] \mathrm{EF} 1$ proved an excellent radiotracer for non-invasive imaging of tumour hypoxia [68].

\section{(h) $\left[{ }^{124} I\right]$ IAZA ([$\left.{ }^{124} I\right]$ iodoazomycin arabinoside)}

Although IAZA has been frequently labelled with gamma rays-emitting isotopes of iodine $\left(\left[{ }^{123} \mathrm{I}\right]\right.$ and $\left.\left[{ }^{125} \mathrm{I}\right]\right)$, several studies report on the use of IAZA labelled with $\left[{ }^{124} \mathrm{I}\right]$. In a recent study by Reischl et al., the hypoxia imaging capacities of $\left[{ }^{124} \mathrm{I}\right] \mathrm{IAZA},\left[{ }^{18} \mathrm{~F}\right] \mathrm{FAZA}$ and $\left[{ }^{18} \mathrm{~F}\right]$ FMISO were compared in female Balb/c nude mice bearing A431 tumours with a small animal PET scanner. $\left[{ }^{18} \mathrm{~F}\right]$ FAZA displayed significantly higher tumour to background ratio compared to $\left[{ }^{18} \mathrm{~F}\right] \mathrm{MISO}$ and $\left[{ }^{124} \mathrm{I}\right] \mathrm{IAZA}$. Although the tumour to background ratio for $\left[{ }^{124} \mathrm{I}\right] \mathrm{IAZA}$ increased with time, ratios were still lower than those for $\left[{ }^{18} \mathrm{~F}\right] \mathrm{FAZA}$ at shorter time periods. The study demonstrated the superior biokinetics of $\left[{ }^{18} \mathrm{~F}\right] \mathrm{FAZA}$ compared to $\left[{ }^{18} \mathrm{~F}\right] \mathrm{FMISO}$ and $\left[{ }^{124}\right.$ I]IAZA [44].

Newer agents based on the azomycin-nucleoside structure such as iodoazomycin galactoside (IAZG) $[69,70]$ and iodoazomycin galactopyranoside (IAZGP) [71] have been developed and evaluated. Two studies compared $\left[{ }^{124} \mathrm{I}\right]$ IAZG uptake with $\left[{ }^{18} \mathrm{~F}\right] \mathrm{FMISO}$ uptake. Zanzonico et al. studied the use of $\left[{ }^{124} \mathrm{I}\right] \mathrm{IAZG}$ as a hypoxia imaging agent in $\mathrm{MCa}$ and FsalI tumour-bearing mice using microPET imaging by comparing it with $\left[{ }^{18} \mathrm{~F}\right] \mathrm{FMISO}$ imaging and provided data showing the potential of this tracer for hypoxia imaging [69]. A similar study by Riedl et al. in Morris hepatoma (RH7777)-bearing nude rats, however, found that although $\left[{ }^{18} \mathrm{~F}\right]$ FMISO localized in the same intratumoural regions as $\left[{ }^{124} \mathrm{I}\right] \mathrm{IAZG}$, a superior diagnostic image quality was obtained with $\left[{ }^{18} \mathrm{~F}\right] \mathrm{FMISO}[70]$. A recent study evaluated hypoxia imaging using [ $\left.{ }^{124} \mathrm{I}\right]$ IAZGP in a Morris hepatoma RH7777 tumour rat model by comparing it with fluorescence fiberoptic oxygen probe measurements, pimonidazole and EF5 distribution and tried to determine the optimal time after injection to depict hypoxia. $\left[{ }^{124} \mathrm{I}\right] \mathrm{IAZG}$ distribution correlated positively with pimonidazole and EF5 distributions, and the optimal ratio between signal intensity and tumour to liver contrast occurred $6 \mathrm{~h}$ after tracer administration [71].

2. Non-imidazole imaging agents

(a) $\left[{ }^{18} \mathrm{~F}\right]$ FDG (2-deoxy-2- $\left[{ }^{18} \mathrm{~F}\right]$ fluoro-D-glucose)

$\left[{ }^{18} \mathrm{~F}\right]$ FDG-PET is a non-invasive functional imaging method that is routinely used for cancer detection, staging and monitoring of response in several tumour types. Because the uptake of $\left[{ }^{18} \mathrm{~F}\right] \mathrm{FDG}$ during FDG PET imaging relies largely on the expression of proteins that are under control of HIF-1, the degree of $\left[{ }^{18} \mathrm{~F}\right] \mathrm{FDG}$ uptake by tumours might indirectly reflect the level of hypoxia. Reports trying to relate $\left[{ }^{18} \mathrm{~F}\right] \mathrm{FDG}$ uptake with tumour hypoxia have, however, given inconsistent results. In vitro studies have suggested that FDG should be accumulated in hypoxic cancer cells compared to normoxic cancer cells because of changed metabolism [21, 47, 72-77]. However, in vivo experiments (pre-clinical and clinical) have given conflicting results when showing a correlation between the uptake of $\left[{ }^{18} \mathrm{~F}\right] \mathrm{FDG}$ and the existence of hypoxia in tumours [18-20, 22, 27-29, 32-35, 40, 78-84]. A recent review by Dierckx et al. addresses this subject matter [85].

\section{(b) Cu-ATSM}

Another alternative PET agent for hypoxia imaging that holds great promise is based on a metal complex of radioactive copper with ATSM, diacetyl-bis $\left(N^{4}\right.$-methylthiosemicarbazone). $\mathrm{Cu}$ (II)-ATSM is a neutral lipophilic molecule, which is highly membrane permeable. It can undergo reduction by cellular reducing equivalents and can be converted to 
$[\mathrm{Cu}(\mathrm{I})-\mathrm{ATSM}]^{-}$, which becomes entrapped in cells because of its negative charge when cells are hypoxic. There are four different positron-emitting copper isotopes that each have their own decay scheme: ${ }^{60} \mathrm{Cu}\left(\mathrm{t}_{1 / 2}=0.40 \mathrm{~h}\right),{ }^{61} \mathrm{Cu}\left(\mathrm{t}_{1 / 2}=\right.$ $3.32 \mathrm{~h}),{ }^{62} \mathrm{Cu}\left(\mathrm{t}_{1 / 2}=0.16 \mathrm{~h}\right),{ }^{64} \mathrm{Cu}\left(\mathrm{t}_{1 / 2}=12.7 \mathrm{~h}\right)[86]$.

Pre-clinical data: After reports on the use of $\mathrm{Cu}^{62}$-ATSM to detect hypoxia in hypoxic myocardial tissue [87], numerous pre-clinical studies have evaluated and validated its use for imaging of hypoxia in tumours. In an in vitro study by Dearling et al., several ${ }^{64} \mathrm{Cu}$-labelled bis (thiosemicarbazone) complexes were prepared and tested for tumour hypoxia selectivity by incubation with $\mathrm{CHO} 320$ Chinese hamster ovary cells under normoxic and hypoxic conditions. A number of molecules, including ${ }^{64} \mathrm{Cu}-\mathrm{ATSM}$, showed significant hypoxia selectivity [88]. Later, attempts were made to improve the hypoxia selectivity of the copper complexes by identification of the physicochemical properties that control hypoxia selectivity [89]. Lewis et al. evaluated ${ }^{64} \mathrm{Cu}$-ATSM in vitro in the EMT6 carcinoma cell line under varying $\mathrm{pO}_{2}$ and compared it with $\left[{ }^{18} \mathrm{~F}\right] \mathrm{FMISO}$ and further evaluated ${ }^{64} \mathrm{Cu}$-ATSM in vivo in a murine animal model. ${ }^{64} \mathrm{Cu}$-ATSM was selectively trapped in vitro in EMT6 cells under hypoxic conditions and in vivo in solid EMT6 tumours, confirming its role as an agent to successfully detect tumour hypoxia [90]. A study by Burgman et al. indicated, after determining the in vitro uptake of ${ }^{64} \mathrm{Cu}$ ATSM as a function of oxygenation conditions and incubation time in several tumour cell lines of rodent and human origin, that the uptake and retention of ${ }^{64} \mathrm{Cu}$-ATSM and their relation to oxygenation conditions were cell line dependent [91]. The $\mathrm{pO}_{2}$ dependence of Cu-ATSM was confirmed in a 9L gliosarcoma rat model by comparison of $\mathrm{Cu}$-ATSM uptake with direct oxygen measurements using needle oxygen electrodes while tumour oxygen concentration was manipulated [92]. A study by Yuan et al., on the other hand, concluded after comparing the autoradiographic distributions of ${ }^{64} \mathrm{Cu}$-ATSM with the hypoxia markers EF5, pimonidazole and CAIX in R3230 mammary adenocarcinomas, fibrosarcomas and 9L gliomas that ${ }^{64} \mathrm{Cu}-\mathrm{ATSM}$ is a suitable PET hypoxia marker in most tumour types, but not for all [93].

A number of studies compared ${ }^{64} \mathrm{Cu}$-ATSM uptake with $\left[{ }^{18} \mathrm{~F}\right]$ FMISO uptake and $\left[{ }^{18} \mathrm{~F}\right] \mathrm{FDG}$ uptake in vivo. O'Donoghue et al. reported that the uptake of ${ }^{64} \mathrm{Cu}$-ATSM $4 \mathrm{~h}$ after injection in an R3327-AT anaplastic rat prostate tumour model did not correlate with $\left[{ }^{18} \mathrm{~F}\right] \mathrm{FMISO}$ uptake and does not reflect the level of hypoxia, as assessed by pimonidazole immunostaining and invasive oxygen needle probes. ${ }^{64} \mathrm{Cu}$-ATSM imaging at $16-20 \mathrm{~h}$ after injection, however, corresponded with $\left[{ }^{18} \mathrm{~F}\right] \mathrm{FMISO}$ uptake and showed a good correlation with the distribution of tumour hypoxia. In a $\mathrm{FaDu}$ tumour model, early and late ${ }^{64} \mathrm{Cu}-$ ATSM images were in concordance with $\left[{ }^{18} \mathrm{~F}\right] \mathrm{FMISO}$ imaging, indicating a tumour-specific dependence of ${ }^{64} \mathrm{Cu}$-ATSM uptake and retention under hypoxic conditions [94]. In another study, ${ }^{64} \mathrm{Cu}$-ATSM tumour uptake was unable to predictably detect changes in varying amounts of tumour hypoxia when oxygenation levels in SCCVII tumours were modulated, whereas $\left[{ }^{18} \mathrm{~F}\right] \mathrm{FMISO}$ tumour uptake was more responsive to changing levels of hypoxia. Tumour hypoxia was also assessed independently using pimonidazole [95].

Two studies comparing ${ }^{64} \mathrm{Cu}$-ATSM uptake with $\left[{ }^{18} \mathrm{~F}\right]$ FDG uptake in different animal models concluded that both tracers have a different distribution pattern $[81,82] .{ }^{64} \mathrm{Cu}$ ATSM accumulated in hypoxic but viable tumour cells, whereas $\left[{ }^{18} \mathrm{~F}\right] \mathrm{FDG}$ uptake was highest in pre-necrotic regions where the cells were believed to lack the necessary reductive mechanisms to accumulate ${ }^{64} \mathrm{Cu}$-ATSM [81]. It was also shown that regions with high ${ }^{64} \mathrm{Cu}$-ATSM uptake were hypovascular and consisted of tumour cells arrested in the cell cycle, whereas regions with high $\left[{ }^{18} \mathrm{~F}\right] \mathrm{FDG}$ uptake were hypervascular and consisted of proliferating cells, as confirmed by histological analysis with Ki67, CD34 and TUNEL assay [82]. Finally Dence et al. compared the regional distribution of ${ }^{64} \mathrm{Cu}-\mathrm{ATSM},\left[{ }^{18} \mathrm{~F}\right] \mathrm{FDG}$ and $\left[{ }^{18} \mathrm{~F}\right]$ FMISO in 9L gliosarcoma tumours. It was shown that the regional distribution of $\left[{ }^{18} \mathrm{~F}\right] \mathrm{FMISO}$ at $2 \mathrm{~h}$ correlates highly with the distribution of ${ }^{64} \mathrm{Cu}$-ATSM at $10 \mathrm{~min}$ or $24 \mathrm{~h}$. A poor correlation existed however between ${ }^{64} \mathrm{Cu}$-ATSM (10 min) and $\left[{ }^{18} \mathrm{~F}\right] \mathrm{FDG}[22]$.

Clinical data: In numerous studies, ${ }^{60} \mathrm{Cu}$-ATSM uptake proved to be predictive of tumour behaviour and response to therapy in patients with non-small cell lung cancer [83], cervical cancer [96, 97] and rectal carcinoma [84]. In a study by Dehdashti et al. in 14 patients with biopsy-proven cervical cancer, an arbitrarily selected tumour to muscle threshold of 3.5 was able to discriminate those patients that were likely to develop recurrence so that ${ }^{60} \mathrm{Cu}$-ATSM uptake was inversely related to progression-free survival and overall survival. Additionally, no correlation was found between ${ }^{60} \mathrm{Cu}$-ATSM uptake and $\left[{ }^{18} \mathrm{~F}\right] \mathrm{FDG}$ uptake [96]. To confirm these results, a study with a larger group of patients was performed by the same group. Tumour ${ }^{60} \mathrm{Cu}$-ATSM uptake (T/M threshold of 3.5) in 38 patients with cervical cancer was inversely related to progression-free survival and cause-specific survival. Again, no correlation was found between ${ }^{60} \mathrm{Cu}$-ATSM uptake and $\left[{ }^{18} \mathrm{~F}\right]$ FDG uptake [97]. Similar results were obtained in a study where semiquantitative analysis of the ${ }^{60} \mathrm{Cu}$-ATSM tumour to muscle ratio in 14 patients with non-small cell lung cancer was able to discriminate responders from non-responders. However, there was no significant difference in mean tumour SUV of non-responders and responders. Again, no correlation was found between ${ }^{60} \mathrm{Cu}$-ATSM uptake and $\left[{ }^{18} \mathrm{~F}\right]$ FDG uptake [83]. In a recent study, an effort was made 
to predict the response of rectal cancers to neoadjuvant chemoradiotherapy and prognosis in 17 patients. The results of this small pilot study suggested that ${ }^{60} \mathrm{Cu}$-ATSM tumour to muscle ratio may be predictive of survival and, possibly, tumour response. Again, no correlation was found between ${ }^{60} \mathrm{Cu}$-ATSM uptake and $\left[{ }^{18} \mathrm{~F}\right] \mathrm{FDG}$ uptake [84]. To determine if hypoxia-related molecular markers were associated with ${ }^{60} \mathrm{Cu}$-ATSM retention, the PET imaging data of 15 patients with cancer of the cervix were compared with the expression of tissue molecular markers, which included VEGF, cyclo-oxygenase-2 (COX-2), epidermal growth factor receptor (EGFR), carbonic anhydrase IX (CA-9) and apoptotic index. Hypoxia as identified with ${ }^{60} \mathrm{Cu}-\mathrm{ATSM}$ imaging was correlated with overexpression of VEGF, EGFR, COX-2, CA-9, an increase in apoptosis and a poor outcome [98]. Chao et al. further demonstrated the feasibility of using ${ }^{60} \mathrm{Cu}$-ATSM imaging to identify the hypoxic tumour subvolume through coregistration of CT and ${ }^{60} \mathrm{Cu}-\mathrm{ATSM}$ PET images in order to plan a patient's course of radiotherapy and perform intensity-modulated radiation therapy (IMRT) [99]. As most clinical Cu-ATSM studies used the agent with the short-lived positron-emitting radionuclide of copper, ${ }^{60} \mathrm{Cu}$, a recent study compared the image quality and tumour uptake of ${ }^{60} \mathrm{Cu}$-ATSM and ${ }^{64} \mathrm{Cu}$-ATSM in ten patients with cervical carcinoma to evaluate the use of $\mathrm{Cu}$-ATSM with one of the longer-lived positron-emitting copper nuclides, ${ }^{64} \mathrm{Cu}$. It was concluded that ${ }^{64} \mathrm{Cu}$-ATSM was a safe radiopharmaceutical that can be used to obtain high quality images of tumour hypoxia in human cancers [100].

\section{Non-invasive measurement of tumour hypoxia with SPECT}

\author{
1. $\left[{ }^{123} \mathrm{I}\right] \mathrm{IAZA}$ and $\left[{ }^{125} \mathrm{I}\right] \mathrm{IAZA}\left(\left[\left[^{123} \mathrm{I}\right] /\left[{ }^{125} \mathrm{I}\right]\right.\right.$ iodoazomycin \\ arabinoside)
}

Pre-clinical data: In one of the first studies with IAZA, its synthesis and labelling with $\left[{ }^{125} \mathrm{I}\right]$ was described. Its elimination and biodistribution were also studied in vivo in EMT-6 tumours in BALB/c mice, and it was shown that IAZA undergoes hypoxia-dependent binding in EMT-6 cells in vitro [101]. Moore et al. investigated the oxygenation status and tumour perfusion of rats with Dunning R3327-AT tumours who were treated with photodynamic therapy (PDT) with $\left[{ }^{123} \mathrm{I}\right] \mathrm{IAZA}$ and $\left[{ }^{99 \mathrm{~m}} \mathrm{Tc}\right] \mathrm{HMPAO}$. Increased retention of $\left[{ }^{123} \mathrm{I}\right]$ IAZA was observed in tumours treated with PDT together with an inverse correlation between tumour hypoxia as measured with $\left[{ }^{123} \mathrm{I}\right] \mathrm{IAZA}$ and tumour perfusion as measured with $\left[{ }^{99 \mathrm{~m}} \mathrm{Tc}\right] \mathrm{HMPAO}$ [102].

Clinical data: The first clinical study assessing hypoxia with IAZA investigated the uptake of $\left[{ }^{123}\right.$ I]IAZA in patients with advanced malignancies. Radiotracer avidity was observed in three of ten tumours, and it was concluded that the use of gamma emitter-labelled 2-nitroimidazoles as diagnostic radiopharmaceuticals is feasible and safe and that metabolic binding of $\left[{ }^{123}\right.$ I]IAZA is observed in some, but not all tumours [103]. In 22 patients, $\left[{ }^{123} \mathrm{I}\right] \mathrm{IAZA}$ uptake showed a significant inverse correlation with the perfusion marker $\left[{ }^{99 \mathrm{~m}} \mathrm{Tc}\right] \mathrm{HMPAO}$, and severe perfusion deficits were usually associated with an increased uptake of the hypoxic marker [104]. After observing uptake of radioactivity in the brain after administration of $\left[{ }^{123} \mathrm{I}\right] \mathrm{IAZA}$, a study was undertaken to investigate the proposed metabolites of IAZA in normal and tumour-bearing murine models. Neither of the proposed metabolites' biodistribution did support its involvement in brain radioactivity uptake in patients [105]. A study investigating the use of $\left[{ }^{123} \mathrm{I}\right] \mathrm{IAZA}$ in 51 human patients with newly diagnosed malignancies demonstrated hypoxia in small cell lung cancer and squamous cell carcinoma of head and neck but not in malignant gliomas. The study did, however, demonstrate the feasibility of $\left[{ }^{123} \mathrm{I}\right]$ IAZA imaging in a clinical setting [106]. Stypinski et al. reported the clinical pharmacokinetics of IAZA, the radiopharmacokinetics of $\left[{ }^{123} \mathrm{I}\right] \mathrm{IAZA}$, total radioactivity kinetics and the radiation dosimetry estimates for six healthy volunteers and concluded that all supported its clinical use for imaging tissue hypoxia [107, 108].

Newer agents based on the azomycin-nucleoside structure such as IAZG $[109,110]$, iodoazomycin pyranoside (IAZP) [111], IAZGP [112, 113] and iodoazomycin xylopyranoside (IAZXP) [109] have been developed and evaluated. Iyer et al. demonstrated that microelectrode measurements in R3327-AT tumour-bearing rats did not correlate with $\left[{ }^{125}\right.$ I]IAZGP uptake [112]. Furthermore, a study by Saitoh et al. showed high accumulation of IAZGP in FM3A mouse tumours $24 \mathrm{~h}$ after administration [113].

2. ${ }^{99 \mathrm{~m}}$ Tc-labelled agents

\section{(a) BMS 181321}

This was the first ${ }^{99 \mathrm{~m}} \mathrm{Tc}$-labelled 2-nitroimidazole to be widely studied for imaging [114]. A number of experimental studies have evaluated the use of BMS 181321 for the detection of ischaemic and hypoxic myocardium [115-118]. Ballinger et al. showed selective accumulation in hypoxic cells in vitro and in vivo but concluded that BMS 181321 was not optimal for tumour hypoxia imaging because of in vitro and in vivo instabilities and a high partition coefficient, resulting in slow clearance from the blood and high background levels in normal tissues [119].

\section{(b) BRU59-21}

Pre-clinical data: BRU59-21, previously known as BMS 194796, is a second-generation analogue of BMS 181321 which shows greater stability in vitro and more rapid 
clearance from the circulation in vivo, resulting in higher tumour to blood and tumour to muscle ratios. It showed selective localization in tumour cells incubated under hypoxic conditions and following intravenous injection in animal models representative of poorly perfused tumours [120]. In a study by Zhang et al., BRU59-21 and HL91 were compared directly in the same in vitro systems. Both tracers proved suitable for hypoxia imaging [121].

Clinical data: Hoebers et al. assessed the safety and biodistribution of $\left[{ }^{99 \mathrm{~m}} \mathrm{Tc}\right] \mathrm{BRU} 59-21$ in ten patients with head and neck cancer and correlated uptake in vivo with pimonidazole staining. In vivo evaluation of tumour hypoxia with $\left[{ }^{99 m} \mathrm{Tc}\right]$ BRU59-21 appeared to be safe and feasible, and uptake and retention of the marker seemed to be indicative of tumour hypoxia, as confirmed by pimonidazole staining [122].

\section{(c) $\left[{ }^{99 \mathrm{~m}} \mathrm{Tc}\right] \mathrm{HL}-91$}

Pre-clinical data: Zhang et al. evaluated the efficacy of $\left[{ }^{99 \mathrm{~m}} \mathrm{Tc}\right] \mathrm{HL} 91$ as a non-invasive marker of tumour hypoxia in vitro (Chinese hamster ovary cells) and in vivo $(\mathrm{C} 3 \mathrm{H}$ mice bearing KHT-C tumours) and observed selective accumulation of $\left[{ }^{99 \mathrm{~m}} \mathrm{Tc}\right] \mathrm{HL} 91$ in hypoxic cells and hypoxic tumours [123]. A similar study assessed the retention of $\left[{ }^{99 \mathrm{~m}} \mathrm{Tc}\right] \mathrm{HL} 91$ in mice bearing three different tumours under control and enhanced oxygenation conditions and correlated these data with the oxygenation status as assessed by Eppendorf $\mathrm{pO}_{2}$ histograph measurements. A very good correlation between $\left[{ }^{99 \mathrm{~m}} \mathrm{Tc}\right] \mathrm{HL} 91$ retention and hypoxia, as measured by the Eppendorf histograph, was observed [124]. Yutani et al. found that $\left[{ }^{99 \mathrm{~m}} \mathrm{Tc}\right] \mathrm{HL} 91$ accumulated to significantly higher levels in hypoxic tumour areas and that $\left[{ }^{99 \mathrm{~m}} \mathrm{Tc}\right]$ HL91 uptake was strongly correlated with the expression of GLUT1 in the viable cancer cell area [125]. In a study by Tatsumi et al., a dual-tracer autoradiography was performed with HL91 and IAP $\left({ }^{14} \mathrm{C}\right.$-iodoantipyrine $)$ in Walker 256 tumour-bearing rats to elucidate the relationship between hypoxia and blood flow. The study confirmed that high HL91 uptake is related to low blood flow [126]. Kinuya et al. reported on an increase in $\left[{ }^{99 \mathrm{~m}} \mathrm{Tc}\right] \mathrm{HL} 91$ uptake after exposure to X-ray radiation [127]. Siim et al. examined whether $\left[{ }^{99 \mathrm{~m}} \mathrm{Tc}\right] \mathrm{HL} 91$ uptake could be used as a marker for the inhibition of tumour blood flow by the antivascular agents DMXAA (5,6-dimethylxantenone-4-acetic acid) and CA4P (combretastatin A4 phosphate) and observed that tumour hypoxia as a result of the acute inhibition of blood flow by antivascular agents caused increased tumour uptake of $\left[{ }^{99 \mathrm{~m}} \mathrm{Tc}\right] \mathrm{HL} 91$ [128]. Another study demonstrated that microelectrode measurements in R3327-AT tumour-bearing rats did not correlate with $\left[{ }^{99 m}\right.$ Tc]HL91 uptake [112]. After having determined the biodistribution of $\left[{ }^{99 \mathrm{~m}} \mathrm{Tc}\right] \mathrm{HL} 91$ [129], Suzuki et al. investigated the relationship between [ ${ }^{99 \mathrm{~m}} \mathrm{Tc}$ ] HL91 uptake and tumour response to radiation in athymic mice bearing different human tumours. They concluded that $\left[{ }^{99 \mathrm{~m}} \mathrm{Tc}\right]$ HL91 uptake did not always relate to their sensitivities to radiation therapy [130]. In a study by Kinuya et al., an attempt was made to determine whether oxygenation status affected $\left.{ }^{99 \mathrm{~m}} \mathrm{Tc}\right] \mathrm{MIBI}$ (sestamibi) uptake. They observed enhanced $\left[{ }^{99 \mathrm{~m}} \mathrm{Tc}\right] \mathrm{HL} 91$ accumulation in hypoxic tumour cells after treatment with $\mathrm{N}_{2}$ gas (in vitro) and hydralazine (in vivo) [131]. A recent study by Lee et al. investigated the selectivity of $\left[{ }^{99 \mathrm{~m}} \mathrm{Tc}\right] \mathrm{HL} 91$ for hypoxia in vitro in A549 human lung cancer cells and LL2 murine Lewis lung cancer cells under varying oxygen concentrations and in vivo in different xenograft mouse models after chemically altering the degree of tumour hypoxia with hydralazine. The in vitro studies identified hypoxiaselective uptake of $\left[{ }^{99 \mathrm{~m}} \mathrm{Tc}\right] \mathrm{HL} 91$, with significantly increased uptake in the hypoxic state compared to the normoxic state. The in vivo studies showed that $\left[{ }^{99 m} \mathrm{Tc}\right]$ HL91 was markedly increased in mice treated with hydralazine compared with controls [132].

Clinical data: Clinical studies concerning the clinical evaluation of $\left[{ }^{99 \mathrm{~m}} \mathrm{Tc}\right] \mathrm{HL} 91$ are limited. In a pilot study, Cook et al. compared $\left[{ }^{99 \mathrm{~m}} \mathrm{Tc}\right] \mathrm{HL} 91$ uptake with $\left[{ }^{18} \mathrm{~F}\right] \mathrm{FDG}$ PET imaging in ten patients with a variety of tumours and showed visible $\left[{ }^{99 \mathrm{~m}} \mathrm{Tc}\right] \mathrm{HL} 91$ tumour uptake in all seven patients where the tumour could be clearly identified with $\left[{ }^{18}\right.$ F]FDG PET [133]. Another phase I pilot study evaluated the usefulness of $\left[{ }^{99 \mathrm{~m}} \mathrm{Tc}\right] \mathrm{HL} 91$ imaging for the visualization of local recurrence in nine men with squamous cell carcinoma of the head and neck (SCCHN) as compared to CT and biopsy and concluded that $\left[{ }^{99 \mathrm{~m}} \mathrm{Tc}\right] \mathrm{HL} 91$ is a safe radioligand and that metabolic binding in a large fraction but not all of local SCCHN recurrences may be expected [134]. Finally, in a study with 32 patients with non-small cell lung cancer, Li et al. showed that hypoxia imaging with $\left[{ }^{99 \mathrm{~m}} \mathrm{Tc}\right] \mathrm{HL} 91$ before radiotherapy may predict tumour response and patient survival [135].

\section{Discussion}

There are several prerequisites to which the ideal noninvasive hypoxic marker should comply: (1) It should be specific for hypoxia and thus distinguish normoxia, hypoxia and anoxia or necrosis. (2) It should image acute and chronic hypoxia and possibly distinguish between both. (3) It should be simple, non-toxic, fast, easy to perform and allow repeated measurements. (4) It should be lipophilic to have a homogeneous biodistribution in all tissues including tumours but at the same time hydrophilic to have a faster elimination, thus allowing larger tumour to normal tissue ratio of radioactivity. (5) It should have little hypoxiaindependent degradation in vivo leading to non-specific tracer metabolites and/or little aspecific tissue binding, so 
that only oxygen-specific retention mechanisms determine the amount of tracer that is temporarily or permanently trapped. (6) It should reflect intracellular $\mathrm{pO}_{2}$ rather than blood flow or some consequence of subsequent biochemistry. (7) It should be sensitive at $\mathrm{pO}_{2}$ levels relevant to tumour therapy. (8) It should offer the ability to quantify. Unfortunately, none of the present hypoxia tracers available completely fulfils these requirements.

Although SPECT is more commonly used than PET, and, in particular, ${ }^{99 \mathrm{~m}} \mathrm{Tc}$ has a number of practical advantages that include ready availability at low cost, convenient half-life for hypoxia measurements and versatile chemistry as compared with ${ }^{18} \mathrm{~F}$, the superior spatial resolution and more accurate quantitation with PET makes the latter a better candidate for detection of tumoural hypoxia. Of all the PET tracers that are being evaluated as possible markers of tumour hypoxia, only three have been thoroughly evaluated in a clinical situation: $\left[{ }^{18} \mathrm{~F}\right] \mathrm{FMISO}$, $\left[{ }^{18} \mathrm{~F}\right] \mathrm{FDG}$ and $\mathrm{Cu}-\mathrm{ATSM}$.

$\left[{ }^{18} \mathrm{~F}\right] \mathrm{FMISO}$ is the most widely used and investigated hypoxia marker and has been validated in multiple studies both in humans and animals. Studies using $\left[{ }^{18} \mathrm{~F}\right]$ FMISO have demonstrated variable, but significant levels of hypoxia in several tumour types. In addition, $\left[{ }^{18} \mathrm{~F}\right] \mathrm{FMISO}$ PET imaging has been used as a prognostic indicator in several other studies. It has, however, failed to gain wider acceptance for routine clinical application because of a number of limitations such as: (1) slow accumulation in hypoxic tumours; (2) a low target to background ratio due to high non-specific binding resulting from its relatively high lipophilicity; and (3) significant non-oxygen dependent metabolism leading to a considerable amount of radioactive metabolite products.

Several studies have tried to validate $\left[{ }^{18} \mathrm{~F}\right] \mathrm{FDG}$ as an alternative marker for hypoxia imaging. The rationale behind this is that $\left[{ }^{18} \mathrm{~F}\right] \mathrm{FDG}$ uptake during FDG PET imaging relies largely on the expression of proteins that are under control of HIF-1. As a result, the degree of $\left[{ }^{18} \mathrm{~F}\right] \mathrm{FDG}$ uptake by tumours might indirectly reflect the level of hypoxia. This would obviate the need for more specific radiopharmaceuticals for hypoxia imaging. Reports trying to relate $\left[{ }^{18} \mathrm{~F}\right] \mathrm{FDG}$ uptake with tumour hypoxia have given inconsistent results. In vitro studies have suggested that FDG is preferably accumulated in hypoxic cancer cells compared to normoxic cancer cells because of changed metabolism. However, in vivo experiments (pre-clinical and clinical) have given conflicting results when showing a correlation between the uptake of $\left[{ }^{18} \mathrm{~F}\right] \mathrm{FDG}$ and the existence of hypoxia in tumours. It appears that in those tumours where HIF-1 activation is mainly hypoxia driven, the degree of $\left[{ }^{18} \mathrm{~F}\right] \mathrm{FDG}$ uptake may be a surrogate marker of hypoxia. Further evaluation of $\left[{ }^{18} \mathrm{~F}\right] \mathrm{FDG}$ uptake by various tumour types in relation with invasive and non- invasive markers of tumour hypoxia is needed to fully elucidate the role of $\left[{ }^{18} \mathrm{~F}\right] \mathrm{FDG}$ as a marker of tumour hypoxia. Furthermore, most studies to date assessing the value of FDG as a measure of hypoxia calculated SUV. Possibly, dynamic PET studies and compartment analysis may offer an advantage over standard uptake measurements.

The molecule that holds the greatest promise for the future is $\mathrm{Cu}$-ATSM. Although its mechanism of hypoxic retention is not yet fully elucidated, numerous in vitro and in vivo studies have shown its selectivity for hypoxic tissue. It has a small molecular weight and a high cell membrane permeability allowing it to diffuse easily from the bloodstream to surrounding cells. This combined with a rapid blood clearance and its rapid reduction and retention in hypoxic tissues ensures that $\mathrm{Cu}$-ATSM shows a rapid delineation of tumour hypoxia and high tumour to background ratios. Clinical results clearly suggest further clinical evaluation is warranted and positive results are expected to follow.

\section{Conclusion}

As the importance of tumour hypoxia is being recognized, so is the importance of its detection. Because of the limitations of the current gold standard, a non-invasive technique to predict outcome and identify patients with a worse prognosis and/or patients that would benefit from appropriate treatments is needed. Several candidates are rapidly being developed and investigated. Of the several candidate techniques and molecules, each has its advantages and disadvantages, and it may be possible that a particular technique or molecule is best suited for a certain tumour type, grade or stage. Evaluation of the several candidate molecules is taking place in patients at this moment and it is hoped that this eventually will lead to further characterization and optimization.

Open Access This article is distributed under the terms of the Creative Commons Attribution Noncommercial License which permits any noncommercial use, distribution, and reproduction in any medium, provided the original author(s) and source are credited.

\section{References}

1. Vaupel P, Harrison L. Tumor hypoxia: causative factors, compensatory mechanisms, and cellular response. Oncologist 2004;9(Suppl 5):4-9.

2. Vaupel P, Mayer A. Hypoxia in cancer: significance and impact on clinical outcome. Cancer Metastasis Rev 2007;26:225-39.

3. Höckel M, Vaupel P. Tumor hypoxia: definitions and current clinical, biologic, and molecular aspects. J Natl Cancer Inst 2001;93:266-76.

4. Höckel M, Schlenger K, Aral B, Mitze M, Schäffer U, Vaupel P. Association between tumor hypoxia and malignant progression 
in advanced cancer of the uterine cervix. Cancer Res 1996;56:4509-15.

5. Fyles AW, Milosevic M, Wong R, Kavanagh MC, Pintilie M, Sun A, et al. Oxygenation predicts radiation response and survival in patients with cervix cancer. Radiother Oncol 1998;48:149-56.

6. Nordsmark M, Overgaard M, Overgaard J. Pretreatment oxygenation predicts radiation response in advanced squamous cell carcinoma of the head and neck. Radiother Oncol 1996;41:31-9.

7. Brizel DM, Sibley GS, Prosnitz LR, Scher RL, Dewhirst MW. Tumor hypoxia adversely affects the prognosis of carcinoma of the head and neck. Int J Radiat Oncol Biol Phys 1997;38:285-9.

8. Nordsmark M, Bentzen SM, Rudat V, Brizel D, Lartigau E, Stadler P, et al. Prognostic value of tumor oxygenation in 397 head and neck tumors after primary radiation therapy. An international multi-center study. Radiother Oncol 2005;77:18-24.

9. Brizel DM, Scully SP, Harrelson JM, Layfield LJ, Bean JM, Prosnitz LR, et al. Tumor oxygenation predicts for the likelihood of distant metastases in human soft tissue sarcoma. Cancer Res 1996;56:941-3.

10. Lee ST, Scott AM. Hypoxia positron emission tomography imaging with 18F-fluoromisonidazole. Semin Nucl Med 2007;37: 451-61.

11. Krohn KA, Link JM, Mason RP. Molecular imaging of hypoxia. J Nucl Med 2008;49:129S-48S.

12. Kubota K, Tada M, Yamada S, Hori K, Saito S, Iwata R, et al. Comparison of the distribution of fluorine-18 fluoromisonidazole, deoxyglucose and methionine in tumour tissue. Eur J Nucl Med 1999;26:750-7.

13. Rasey JS, Casciari JJ, Hofstrand PD, Muzi M, Graham MM, Chin LK. Determining hypoxic fraction in a rat glioma by uptake of radiolabeled fluoromisonidazole. Radiat Res 2000;153:84-92.

14. Bentzen L, Keiding S, Horsman MR, Grönroos T, Hansen SB, Overgaard J. Assessment of hypoxia in experimental mice tumours by $[18 \mathrm{~F}]$ fluoromisonidazole $\mathrm{PET}$ and $\mathrm{pO} 2$ electrode measurements. Acta Oncol 2002;41:304-12.

15. Dubois L, Landuyt W, Haustermans K, Dupont P, Bormans G, Vermaelen $\mathrm{P}$, et al. Evaluation of hypoxia in an experimental rat tumour model by $[18 \mathrm{~F}]$ fluoromisonidazole PET and immunohistochemistry. Br J Cancer 2004;91:1947-54.

16. Troost EGC, Laverman P, Kaanders JHAM, Philippens M, Lok $\mathrm{J}$, Oyen WJG, et al. Imaging hypoxia after oxygenation modification: comparing [18F]FMISO autoradiography with pimonidazole immunohistochemistry in human xenograft tumors. Radiother Oncol 2006;80:157-64.

17. Troost EGC, Laverman P, Philippens MEP, Lok J, van der Kogel AJ, Oyen WJG, et al. Correlation of [18F]FMISO autoradiography and pimonidazole immunohistochemistry in human head and neck carcinoma xenografts. Eur J Nucl Med Mol Imaging 2008;35: 1803-11. doi:10.1007/s00259-008-0772-7.

18. Bentzen L, Keiding S, Horsman MR, Falborg L, Hansen SB, Overgaard J. Feasibility of detecting hypoxia in experimental mouse tumours with $18 \mathrm{~F}$-fluorinated tracers and positron emission tomography. Acta Oncol 2000;39:629-37.

19. Wyss MT, Honer M, Schubiger PA, Ametamey SM. NanoPET imaging of $[(18) \mathrm{F}]$ fluoromisonidazole uptake in experimental mouse tumours. Eur J Nucl Med Mol Imaging 2006;33:311-8.

20. Zanzonico P, Campa J, Polycarpe-Holman D, Forster G, Finn R, Larson S, et al. Animal-specific positioning molds for registration of repeat imaging studies: comparative microPET imaging of F18-labeled fluoro-deoxyglucose and fluoro-misonidazole in rodent tumors. Nucl Med Biol 2006;33:65-70.

21. Oswald J, Treite F, Hasse C, Kampfrath T, Mäding P, Schwenzer $\mathrm{B}$, et al. Experimental hypoxia is a potent stimulus for radiotracer uptake in vitro: comparison of different tumor cells and primary endothelial cells. Cancer Lett 2007;254:102-10.

22. Dence CS, Ponde DE, Welch MJ, Lewis JS. Autoradiographic and small-animal PET comparisons between (18)F-FMISO, (18)
F-FDG, (18)F-FLT and the hypoxic selective (64)Cu-ATSM in a rodent model of cancer. Nucl Med Biol 2008;35:713-20.

23. Valk PE, Mathis CA, Prados MD, Gilbert JC, Budinger TF. Hypoxia in human gliomas: demonstration by PET with fluorine18-fluoromisonidazole. J Nucl Med 1992;33:2133-7.

24. Rasey JS, Koh WJ, Evans ML, Peterson LM, Lewellen TK, Graham MM, et al. Quantifying regional hypoxia in human tumors with positron emission tomography of [18F]fluoromisonidazole: a pretherapy study of 37 patients. Int J Radiat Oncoly Biol Phys 1996;36:417-28.

25. Bruehlmeier M, Roelcke U, Schubiger PA, Ametamey SM. Assessment of hypoxia and perfusion in human brain tumors using PET with $18 \mathrm{~F}$-fluoromisonidazole and $15 \mathrm{O}-\mathrm{H} 2 \mathrm{O}$. J Nucl Med 2004;45:1851-9.

26. Lawrentschuk N, Poon AM, Foo SS, Johns Putra LG, Murone C, Davis ID, et al. Assessing regional hypoxia in human renal tumours using $18 \mathrm{~F}$-fluoromisonidazole positron emission tomography. BJU Int 2005;96:540-6.

27. Zimny M, Gagel B, DiMartino E, Hamacher K, Coenen HH, Westhofen $\mathrm{M}$, et al. FDG-a marker of tumour hypoxia? A comparison with [18F]fluoromisonidazole and pO2polarography in metastatic head and neck cancer. Eur J Nucl Med Mol Imaging 2006;33:1426-31.

28. Gagel B, Piroth M, Pinkawa M, Reinartz P, Zimny M, Kaiser HJ, et al. pO polarography, contrast enhanced color duplex sonography (CDS), [18F] fluoromisonidazole and [18F] fluorodeoxyglucose positron emission tomography: validated methods for the evaluation of therapy-relevant tumor oxygenation or only bricks in the puzzle of tumor hypoxia? BMC Cancer 2007;7:113-22.

29. Gagel B, Reinartz P, DiMartino E, Zimney M, Pinkawa M, Maneschi $\mathrm{P}$, et al. $\mathrm{pO}(2)$ polarography versus positron emission tomography ([(18)F] fluoromisonidazole, [(18)F]-2-fluoro-2deoxyglucose). An appraisal of radiotherapeutically relevant hypoxia. Strahlenther Onkol 2004;180:616-22.

30. Bentzen L, Keiding S, Nordsmark M, Falborg L, Hansen SB, Keller J, et al. Tumour oxygenation assessed by $18 \mathrm{~F}$ fluoromisonidazole PET and polarographic needle electrodes in human soft tissue tumours. Radiother Oncol 2003;67:339-44.

31. Rajendran JG, Wikson DC, Conrad EU, Peterson LM, Bruckner JD, Rasey JS, et al. [(18)F]FMISO and [(18)F]FDG PET imaging in soft tissue sarcomas: correlation of hypoxia, metabolism and VEGF expression. Eur J Nucl Med Mol Imaging 2003;30:695-704.

32. Rajendran JG, Mankoff DA, O'Sullivan F, Peterson LM, Schwartz DL, Conrad EU, et al. Hypoxia and glucose metabolism in malignant tumors: evaluation by [18F]fluoromisonidazole and [18F]fluorideoxyglucose positron emission tomography imaging. Clin Cancer Res 2004;10:2245-52.

33. Cherk MH, Foo SS, Poon AM, Knight SR, Murone C, Papenfuss AT, et al. Lack of correlation of hypoxic cell fraction and angiogenesis with glucose metabolic rate in non-small cell lung cancer assessed by 18 F-fluoromisonidazole and 18F-FDG PET. J Nucl Med 2006;47:1921-6.

34. Cher LM, Murone C, Lawrentschuk N, Ramdave S, Papenfuss A, Hannah A, et al. Correlation of hypoxic cell fraction and angiogenesis with glucose metabolic rate in gliomas using $18 \mathrm{~F}$ fluoromisonidazole, 18F-FDG PET, and immunohistochemical studies. J Nucl Med 2006;47:410-8.

35. Thorwarth D, Eschmann SM, Holzner F, Paulsen F, Alber M. Combined uptake of [18F]FDG and [18F]FMISO correlates with radiation therapy outcome in head-and-neck cancer patients. Radiother Oncol 2006;80:151-6.

36. Rajendran JG, Schwartz DL, O’Sullivan J, Peterson LM, Ng P, Scharnhorst J, et al. Tumor hypoxia imaging with [F-18] fluoromisonidazole positron emission tomography in head and neck cancer. Clin Cancer Res 2006;12:5435-41. 
37. Eschmann SM, Paulsen F, Reimold M, Dittmann H, Welz S, Reischl G, et al. Prognostic impact of hypoxia imaging with 18Fmisonidazole PET in non-small cell lung cancer and head and neck cancer before radiotherapy. J Nucl Med 2005;46:253-60.

38. Hicks RJ, Rischin D, Fisher R, Binns D, Scott AM, Peters LJ. Utility of FMISO PET in advanced head and neck cancer treated with chemoradiation incorporating a hypoxia-targeting chemotherapy agent. Eur J Nucl Med Mol Imaging 2005;32:1384-91.

39. Rischin D, Hicks RJ, Fisher R, Binns D, Corry J, Porceddu S, et al. Prognostic significance of $[18 \mathrm{~F}]$-misonidazole positron emission tomography-detected tumor hypoxia in patients with advanced head and neck cancer randomly assigned to chemoradiation with or without tirapazamine: a substudy of Trans-Tasman Radiation Oncology Group Study 98.02. J Clin Oncol 2006;24:2098-104.

40. Gagel B, Reinartz P, Demirel C, Kaiser HJ, Zimny M, Piroth M, et al. $[18 \mathrm{~F}]$ fluoromisonidazole and $[18 \mathrm{~F}]$ fluordeoxyglucose positron emission tomography in response evaluation after chemo-/radiotherapy of non-small-cell lung cancer: a feasibility study. BMC Cancer 2006;6:51-8.

41. Nehmeh SA, Lee NY, Schröder H, Squire O, Zanzonico PB, Erdi YE, et al. Reproducibility of intratumor distribution of (18)Ffluoromisonidazole in head and neck cancer. Int $\mathrm{J}$ Radiat Oncol Biol Phys 2008;70:235-42.

42. Sorger D, Patt M, Kumar P, Wiebe LI, Barthel H, Seese A, et al. [18F]Fluoroazomycinarabinofuranoside (18FAZA) and [18F] fluoromisonidazole (18FMISO): a comparative study of their selective uptake in hypoxic cells and PET imaging in experimental rat tumors. Nucl Med Biol 2003;30:317-26.

43. Piert M, Machulla HJ, Picchio M, Reischl G, Ziegler S, Kumar $\mathrm{P}$, et al. Hypoxia-specific tumor imaging with $18 \mathrm{~F}$ fluoroazomycin arabinoside. J Nucl Med 2005;46:106-13.

44. Reischl G, Dorow DS, Cullinane C, Katsifis A, Roselt P, Binns $\mathrm{D}$, et al. Imaging of hypoxia with [124I]IAZA in comparison with [18F]FMISO and [18F]FAZA - first small animal PET results. J Pharm Pharm Sci 2007;10:203-11.

45. Beck R, Röper B, Carlsen JM, Huisman MC, Lebschi JA, Andratschke N, et al. Pretreatment 18F-FAZA PET predicts success of hypoxia-directed radiochemotherapy using tirapazamine. J Nucl Med 2007;48:973-80.

46. Busk M, Horsman MR, Jakobsen S, Keiding S, van der Kogel AJ, Bussink J, et al. Imaging hypoxia in xenografted and murine tumors with $18 \mathrm{~F}$-fluoroazomycin arabinoside: a comparative study involving microPET, autoradiography, pO2-polarography, and fluorescence microscopy. Int J Radiat Oncol Biol Phys 2008;70: 1202-12.

47. Busk M, Horsman MR, Jakobsen S, Bussink J, van der Kogel A, Overgaard J. Cellular uptake of PET tracers of glucose metabolism and hypoxia and their linkage. Eur J Nucl Med Mol Imaging 2008;35:2294-303. doi:10.1007/s00259-008-0888-9.

48. Souvatzoglou M, Grosu AL, Röper B, Krause BJ, Beck R, Reischl G, et al. Tumour hypoxia imaging with [18F]FAZA PET in head and neck cancer patients: a pilot study. Eur J Nucl Med Mol Imaging 2007;34:1566-75.

49. Grosu AL, Souvatzoglu M, Röper B, Dobritz M, Wiedenmann $\mathrm{N}$, Jacob $\mathrm{V}$, et al. Hypoxia imaging with FAZA-PET and theoretical considerations with regard to dose painting for individualization of radiotherapy in patients with head and neck cancer. Int J Radiat Oncol Biol Phys 2007;69:541-51.

50. Rasey JS, Hofstrand PD, Chin LK, Tewson TJ. Characterization of [18F]fluoroetanidazole, a new radiopharmaceutical for detecting tumor hypoxia. J Nucl Med 1999;40:1072-9.

51. Barthel H, Wilson H, Collingridge DR, Brown G, Osman S, Luthra SK, et al. In vivo evaluation of $[18 \mathrm{~F}]$ fluoroetanidazole as a new marker for imaging tumour hypoxia with positron emission tomography. Br J Cancer 2004;90:2232-42.

52. Yang DJ, Wallace S, Cherif A, Li C, Gretzer MB, Kim EE, et al. Development of F-18-labeled fluoroerythronitromidazole as a
PET agent for imaging tumor hypoxia. Radiology 1995;194: 795-800.

53. Grönroos T, Eskola O, Lehtiö K, Minn H, Marjamäki $\mathrm{P}$, Bergman J, et al. Pharmacokinetics of [18F]FETNIM: a potential hypoxia marker for PET. J Nucl Med 2001;42:1397-1404.

54. Grönroos T, Bentzen L, Marjamäki P, Murata R, Horsman MR, Keiding $\mathrm{S}$, et al. Comparison of the biodistribution of two hypoxia markers [18F]FETNIM and [18F]FMISO in an experimental mammary carcinoma. Eur J Nucl Med Mol Imaging 2004;31: 513-20.

55. Tolvanen T, Lehtiö K, Kulmala J, Oikonen V, Eskola O, Bergman $\mathrm{J}$, et al. 18F-Fluoroerythronitroimidazole radiation dosimetry in cancer studies. J Nucl Med 2002;43:1674-80.

56. Lehtiö K, Oikinen V, Grönroos T, Eskola O, Kalliokoski K, Bergman J, et al. Imaging of blood flow and hypoxia in head and neck cancer: initial evaluation with $[(15) \mathrm{O}] \mathrm{H}(2) \mathrm{O}$ and $[(18) \mathrm{F}]$ fluoroerythronitromidazole PET. J Nucl Med 2001;42:1643-52.

57. Lehtiö K, Oikonen V, Nyman S, Grönroos T, Roivainen A, Eskola $\mathrm{O}$, et al. Quantifying tumour hypoxia with fluorine-18 fluoroerythronitroimidazole ([18F]FETNIM) and PET using the tumour to plasma ratio. Eur J Nucl Med Mol Imaging 2003;30:101-8.

58. Lehtiö K, Eskola O, Viljanen T, Oikinen V, Grönroos T, Sillanmäki L, et al. Imaging perfusion and hypoxia with PET to predict radiotherapy response in head-and-neck cancer. Int $\mathrm{J}$ Radiat Oncol Biol Phys 2004;59:971-82.

59. Ziemer LS, Evans SM, Kachur AV, Shuman AL, Cardi CA, Jenkins WT, et al. Noninvasive imaging of tumor hypoxia in rats using the 2-nitroimidazole 18F-EF5. Eur J Nucl Med Mol Imaging 2003;30:259-66.

60. Yapp DTT, Woo J, Kartono A, Sy J, Oliver T, Skov KA, et al. Non-invasive evaluation of tumour hypoxia in the Shionogi tumour model for prostate cancer with $18 \mathrm{~F}-\mathrm{EF} 5$ and positron emission tomography. BJU Int 2007;99:1154-60.

61. Komar G, Seppänen M, Eskola O, Lindholm P, Grönroos TJ, Forsback S, et al. 18F-EF5: a new PET tracer for imaging hypoxia in head and neck cancer. J Nucl Med 2008;49:1944-51.

62. Mahy P, De Bast M, Leveque PH, Gillart J, Labar D, Marchand $\mathrm{J}$, et al. Preclinical validation of the hypoxia tracer 2-(2-nitroimidazol-1-yl)-N-(3, 3, 3-[18F]trifluoropropyl)-acetamide, [18F] EF3. Eur J Nucl Med Mol Imaging 2004;31:1263-72.

63. Mahy P, De Bast M, Gillart J, Labar D, Grégoire V. Detection of tumour hypoxia: comparison between EF5 adducts and [18F] EF3 uptake on an individual mouse tumour basis. Eur J Nucl Med Mol Imaging 2006;33:553-6.

64. Mahy P, De Bast M, de Groot T, Cheguillaume A, Gillart J, Haustermans $\mathrm{K}$, et al. Comparative pharmacokinetics, biodistribution, metabolism and hypoxia-dependent uptake of [18F]-EF3 and [18F]-FMISO in rodent tumor models. Radiother Oncol 2008;89:353-60. doi:10.1016/j.radonc.2008.06.008.

65. Christian N, Bol A, De Bast M, Labar D, Lee J, Mahy P, et al. Determination of tumour hypoxia with the PET tracer [18F]EF3: improvement of the tumour-to-background ratio in a mouse tumour model. Eur J Nucl Med Mol Imaging 2007;34:1348-54.

66. Dubois L, Landuyt W, Cloetens L, Bol A, Bormans G, Haustermans $\mathrm{K}$, et al. [18F]EF3 is not superior to [18F]FMISO for PET-based hypoxia evaluation as measured in a rat rhabdomyosarcoma tumour model. Eur J Nucl Med Mol Imaging 2009;36:209-18. doi:10.1007/s00259-008-x.

67. Mahy P, Geets X, Lonneux M, Levêque P, Christian N, De Bast $\mathrm{M}$, et al. Determination of tumour hypoxia with $[18 \mathrm{~F}] \mathrm{EF} 3$ in patients with head and neck tumours: a phase I study to assess the tracer pharmacokinetics, biodistribution and metabolism. Eur J Nucl Med Mol Imaging 2008;35:1282-9.

68. Evans SM, Kachur AV, Shiue CY, Hustinx R, Jenkins WT, Shive $\mathrm{GG}$, et al. Noninvasive detection of tumor hypoxia using the 2nitroimidazole [18F]EF1. J Nucl Med 2000;41:327-36. 
69. Zanzonico P, O’Donoghue J, Chapman JD, Schneider R, Cai S, Larson S, et al. Iodine-124-labeled iodo-azomycin-galactoside imaging of tumor hypoxia in mice with serial microPET scanning. Eur J Nucl Med Mol Imaging 2004;31:117-28.

70. Riedl CC, Brader P, Zanzonico P, Reid V, Woo Y, Wen B, et al. Tumor hypoxia imaging in orthotopic liver tumors and peritoneal metastasis: a comparative study featuring dynamic $18 \mathrm{~F}-\mathrm{MISO}$ and 124I-IAZG PET in the same study cohort. Eur J Nucl Med Mol Imaging 2007;35:39-46.

71. Riedl CC, Brader P, Zanzonico PB, Chun YS, Woo Y, Singh P, et al. Imaging hypoxia in orthotopic rat liver tumors with iodine 124-labeled iodoazomycin galactopyranoside PET. Radiology 2008;248:561-70.

72. Clavo AC, Brown RS, Wahl RL. Fluorodeoxyglucose uptake in human cancer cell lines is increased by hypoxia. J Nucl Med 1995;36:1625-32.

73. Minn H, Clavo AC, Wahl RL. Influence of hypoxia on tracer accumulation in squamous-cell carcinoma: in vitro evaluation for PET imaging. Nucl Med Biol 1996;23:941-6.

74. Burgman P, Odonoghue JA, Humm JL, Ling CC. Hypoxiainduced increase in FDG uptake in MCF7 cells. J Nucl Med 2001;42:170-5.

75. Pedersen MW, Holm S, Lund EL, Hojgaard L, Kristjansen PE. Coregulation of glucose uptake and vascular endothelial growth factor (VEGF) in two small-cell lung cancer (SCLC) sublines in vivo and in vitro. Neoplasia 2001;3:80-7.

76. Hara T, Bansal A, DeGrado TR. Effect of hypoxia on the uptake of [methyl-3H]choline, $[1-14 \mathrm{C}]$ acetate and $[18 \mathrm{~F}] \mathrm{FDG}$ in cultured prostate cancer cells. Nucl Med Biol 2006;33:977-84.

77. Oswald J, Treite F, Haase C, Kampfrath T, Mäding P, Schwenzer $\mathrm{B}$, et al. Experimental hypoxia is a potent stimulus for radiotracer uptake in vitro: comparison of different tumor cells and primary endothelial cells. Cancer Lett 2007;254:102-10.

78. Dearling J, Flynn A, Sutcliffe-Goulden J, Petrie L, Boden R, Green A, et al. Analysis of the regional uptake of radiolabeled deoxyglucose analogs in human tumor xenografts. J Nucl Med 2004;45:101-7.

79. Pugachev A, Ruan S, Carlin S, Larson SM, Campa J, Ling CC, et al. Dependence of FDG uptake on tumor microenvironment. Int J Radiat Oncol Biol Phys 2005;62:545-53.

80. Scigliano S, Pinel S, Poussier S, Fouyssac F, Plenat F, Karcher $\mathrm{G}$, et al. Measurement of hypoxia using invasive oxygensensitive electrode, pimonidazole binding and 18F-FDG uptake in anaemic or erythropoietin-treated mice bearing human glioma xenografts. Int J Oncol 2008;32:69-77.

81. Obata A, Yoshimoto M, Kasamatsu S, Naiki H, Takamatsu S, Kashikura K, et al. Intra-tumoral distribution of (64)Cu-ATSM: a comparison study with FDG. Nucl Med Biol 2003;30:529-34.

82. Tanaka T, Furukawa T, Fujieda S, Kasamatsu S, Yonekura Y, Fujibayashi Y. Double-tracer autoradiography with Cu-ATSM/ FDG and immunohistochemical interpretation in four different mouse implanted tumor models. Nucl Med Biol 2006;33:74350.

83. Dehdashti F, Mintun MA, Lewis JS, Bradley J, Govindan R, Laforest $\mathrm{R}$, et al. In vivo assessment of tumor hypoxia in lung cancer with 60Cu-ATSM. Eur J Nucl Med Mol Imaging 2003;30:844-50.

84. Dietz DW, Dehdashti F, Grigsby PW, Malyapa RS, Myerson RJ, Picus $\mathrm{J}$, et al. Tumor hypoxia detected by positron emission tomography with $60 \mathrm{Cu}-\mathrm{ATSM}$ as a predictor of response and survival in patients undergoing neoadjuvant chemoradiotherapy for rectal carcinoma: a pilot study. Dis Colon Rectum 2008;51:1641-8.

85. Dierckx RA, Van de Wiele C. FDG uptake, a surrogate of tumour hypoxia? Eur J Nucl Med Mol Imaging 2008;35:1544-9.
86. Vavere AL, Lewis JS. Cu-ATSM: a radiopharmaceutical for the PET imaging of hypoxia. Dalton Trans 2007;43:4893-902. doi:10.1039/b705989b.

87. Fujibayashi Y, Taniuchi H, Yonekura Y, Ohtani H, Konishi J, Yokoyama A. Copper-62-ATSM: a new hypoxia imaging agent with high membrane permeability and low redox potential. J Nucl Med 1997;38:1155-60.

88. Dearling JLJ, Lewis JS, Mullen GED, Rae MT, Zweit J, Blower PJ. Design of hypoxia-targeting radiopharmaceuticals: selective uptake of copper-64 complexes in hypoxic cells in vitro. Eur J Nucl Med 1998;25:788-92.

89. Dearling JLJ, Lewis JS, Mullen GED, Welch MJ, Blower PJ. Copper bis(thiosemicarbazone) complexes as hypoxia imaging agents: structure-activity relationships. J Biol Inorg Chem 2002; 7:249-59.

90. Lewis JS, McCarthy DW, McCarthy TJ, Fujibayashi Y, Welch MJ. Evaluation of 64Cu-ATSM in vitro and in vivo in a hypoxic tumor model. J Nucl Med 1999;40:177-83.

91. Burgman P, O'Donoghue JA, Welch LJS, MJ HJL, Ling CC. Cell line-dependent differences in uptake and retention of the hypoxia-selective nuclear imaging agent Cu-ATSM. Nucl Med Biol 2005;32:623-30.

92. Lewis JS, Sharp TL, Laforest R, Fujibayashi Y, Welch MJ. Tumor uptake of copper-diacetyl-bis(N(4)-methylthiosemicarbazone): effect of changes in tissue oxygenation. J Nucl Med 2001;42:655-61.

93. Yuan H, Schroeder T, Bowsher JE, Hedlund LW, Wong T, Dewhirst MW. Intertumoral differences in hypoxia selectivity of the PET imaging agent $64 \mathrm{Cu}(\mathrm{II})$-diacetyl- bis(N4-methylthiosemicarbazone). J Nucl Med 2006;47:989-98.

94. O’Donoghue JA, Zanzonico P, Pugachev A, Wen B, Smith-Jones P, Cai S, et al. Assessment of regional tumor hypoxia using $18 \mathrm{~F}$ fluoromisonidazole and $64 \mathrm{Cu}$ (II)-diacetyl- bis(N4-methylthiosemicarbazone) positron emission tomography: comparative study featuring microPET imaging, $\mathrm{pO} 2$ probe measurement, autoradiography, and fluorescent microscopy in the R3327-AT and FaDU rat tumor models. Int J Radiat Oncol Biol Phys 2005;61:1493-1502.

95. Matsumoto KI, Szajek L, Krishna MC, Cook JA, Seidel J, Grimes K, et al. The influence of tumor oxygenation on hypoxia imaging in murine squamous cell carcinoma using $[64 \mathrm{Cu}] \mathrm{Cu}-$ ATSM or [18F]fluoromisonidazole positron emission tomography. Int J Oncol 2007;30:873-81.

96. Dehdashti F, Grigsby PW, Mintun MA, Lewis JS, Siegel BA, Welch MJ. Assessing tumor hypoxia in cervical cancer by positron emission tomography with $60 \mathrm{Cu}-\mathrm{ATSM}$ : relationship to therapeutic response - a preliminary report. Int J Radiat Oncol Biol Phys 2003;55:1233-38.

97. Dehdashti F, Grigsby PW, Lewis JS, Laforest R, Siegel BA, Welch MJ. Assessing tumor hypoxia in cervical cancer by PET with $60 \mathrm{Cu}$-labeled diacetyl-bis(N4-methylthiosemicarbazone). J Nucl Med 2008;49:201-5.

98. Grigsby PW, Malyapa RS, Higashikubo R, Schwartz JK, Welch MJ, Huettner PC, et al. Comparison of molecular markers of hypoxia and imaging with (60)Cu-ATSM in cancer of the uterine cervix. Mol Imaging Biol 2007;9:278-83.

99. Chao KSC, Bosch WR, Mutic S, Lewis JS, Dehdashti F, Mintun $\mathrm{MA}$, et al. A novel approach to overcome hypoxic tumor resistance: $\mathrm{Cu}$-ATSM-guided intensity-modulated radiation therapy. Int J Radiat Oncol Biol Phys 2001;49:1171-82.

100. Lewis JS, Laforest R, Dehdashti F, Grigsby PW, Welch MJ, Siegel BA. An imaging comparison of 64Cu-ATSM and 60Cu-ATSM in cancer of the uterine cervix. J Nucl Med 2008;49: 1177-82.

101. Mannan RH, Somayaji VV, Lee J, Mercer JR, Chapman JD, Wiebe LI. Radioiodinated 1-(5-iodo-5-deoxy- $\beta$-D-arabinofuranosyl)-2nitroimidazole (iodoazomycin arabinoside: IAZA): a novel marker of tissue hypoxia. J Nucl Med 1991;32:1764-70. 
102. Moore RB, Chapman JD, Mercer JR, Mannan RH, Wiebe LI, McEwan AJ, et al. Measurement of PDT-induced hypoxia in Dunning prostate tumors by iodine-123-iodoazomycin arabinoside. J Nucl Med 1993;34:405-13.

103. Parliament MB, Chapman JD, Urtasun RC, McEwan AJ, Golberg L, Mercer JR, et al. Non-invasive assessment of human tumour hypoxia with 123I- iodoazomycin arabinoside: preliminary report of a clinical study. Br J Cancer 1992;65:90-5.

104. Groshar D, McEwan AJB, Parliament MB, Urtasun RC, Golberg $\mathrm{LE}$, Hoskinson $\mathrm{M}$, et al. Imaging tumor hypoxia and tumor perfusion. J Nucl Med 1993;34:885-8.

105. Lee HC, Kumar P, McEwan AJ, Wiebe LI, Mercer JR. Synthesis, radiolabeling, and biodistribution of putative metabolites of iodoazomycin arabinoside. Nucl Med Biol 2000;27:61-8.

106. Urtasun RC, Parliament MB, McEwan AJ, Mercer JR, Mannan $\mathrm{RH}$, Wiebe LI, et al. Measurement of hypoxia in human tumours by non-invasive spect imaging of iodoazomycin arabinoside. $\mathrm{Br}$ J Cancer Suppl 1996;27:S209-S12.

107. Stypinski D, Wiebe LI, McEwan AJ, Schmidt RP, Tam YK, Mercer JR. Clinical pharmacokinetics of 123I-IAZA in healthy volunteers. Nucl Med Commun 1999;20:559-67.

108. Stypinski D, McQuarrie SA, Wiebe LI, Tam YK, Mercer JR, McEwan AJB. Dosimetry estimations for 123I-IAZA in healthy volunteers. J Nucl Med 2001;42:1418-23.

109. Chapman JD, Coia LR, Stobbe CC, Engelhardt EL, Fenning MC, Schneider RF. Prediction of tumour hypoxia and radioresistance with nuclear medicine markers. Br J Cancer Suppl 1996;27:S204-S8.

110. Iyer RV, Kim E, Schneider RF, Chapman JD. A dual hypoxic marker technique for measuring oxygenation change within individual tumors. Br J Cancer 1998;78:163-9.

111. Mannan RH, Mercer JR, Wiebe LI, Kumar P, Somayaji VV, Chapman JD. Radioiodinated azomycin pyranoside (IAZP): a novel non-invasive marker for the assessment of tumor hypoxia. J Nucl Biol Med 1992;36:60-7.

112. Iyer RV, Haynes PT, Schneider RF, Movsas B, Chapman D. Marking hypoxia in rat prostate carcinomas with beta-D-[125I] azomycin galactopyranoside and [99mTc]HL-91: correlation with microelectrode measurements. J Nucl Med 2001;42:337-44.

113. Saitoh JI, Sakurai H, Suzuki Y, Muramatsu H, Ishikawa H, Kitamoto $\mathrm{Y}$, et al. Correlations between in vivo tumor weight, oxygen pressure, 31P NMR spectroscopy, hypoxic microenvironment marking by beta-D-iodinated azomycin galactopyranoside (beta-D-IAZGP), and radiation sensitivity. Int J Radiat Oncol Biol Phys 2002;54:903-9.

114. Linder KE, Chan YW, Cyr JE, Malley MF, Nowotnik DP, Nunn AD. TcO(PnA.O-1-(2-nitroimidazole)) [BMS-181321], a new technetium-containing nitroimidazole complex for imaging hypoxia: synthesis, characterization, and xanthine oxidasecatalyzed reduction. J Med Chem 1994;37:9-17.

115. Kusuoka H, Hashimoto K, Fukuchi K, Nishimura T. Kinetics of a putative hypoxic tissue marker, technetium-99m-nitroimidazole (BMS181321), in normoxic, hypoxic, ischemic and stunned myocardium. J Nucl Med 1994;35:1371-6.

116. Shi CQX, Sinusas AJ, Dione DP, Singer MJ, Young LH, Heller EN, et al. Technetium-99m-nitrimidazole (BMS181321): a positive imaging agent for detecting myocardial ischemia. J Nucl Med 1995;36:1078-86.

117. Rumsey WL, Kuczynski B, Patel B, Bauer A, Narra RK, Eaton $\mathrm{SM}$, et al. SPECT imaging of ischemic myocardium using a technetium-99m-nitroimidazole ligand. J Nucl Med 1995;36: $1445-50$

118. Fukuchi K, Kusuoka H, Watanabe Y, Fujiwara T, Nishimura T. Ischemic and reperfused myocardium detected with technetium99m-nitroimidazole. J Nucl Med 1996;37:761-6.
119. Ballinger JR, Kee JWM, Rauth AM. In vitro and in vivo evaluation of a technetium-99m-labeled 2-nitroimidazole (BMS181321) as a marker of tumor hypoxia. J Nucl Med 1996;37:1023-31.

120. Melo T, Duncan J, Ballinger JR, Rauth AM. BRU59-21, a second-generation $99 \mathrm{mTc}$-labeled 2-nitroimidazole for imaging hypoxia in tumors. J Nucl Med 2000;41:169-76.

121. Zhang X, Melo T, Rauth AM, Ballinger JR. Cellular accumulation and retention of the technetium-99m-labelled hypoxia markers BRU59-21 and butylene amine oxime. Nucl Med Biol 2001;28:949-57.

122. Hoebers FJP, Janssen HLK, Olmos RAV, Sprong D, Nunn AD, Balm AJM, et al. Phase 1 study to identify tumour hypoxia in patients with head and neck cancer using technetium-99m BRU 59-21. Eur J Nucl Med Mol Imaging 2002;29:1206-11.

123. Zhang X, Melo T, Ballinger JR, Rauth AM. Studies of $99 \mathrm{mTc}-$ BnAO (HL-91): a non-nitroaromatic compound for hypoxic cell detection. Int J Radiat Oncol Biol Phys 1998;42:737-40.

124. Honess DJ, Hill SA, Collingridge DR, Edwards B, Brauers G, Powell NA, et al. Preclinical evaluation of the novel hypoxic marker 99mTc-HL91 (Prognox) in murine and xenograft systems in vivo. Int J Radiat Oncol Biol Phys 1998;42:731-5.

125. Yutani K, Kusuoka H, Fukuchi K, Tatsumi M, Nishimura T. Applicability of $99 \mathrm{mTc}-\mathrm{HL} 91$, a putative hypoxic tracer, to detection of tumor hypoxia. J Nucl Med 1999;40:854-61.

126. Tatsumi M, Yutani K, Kusuoka H, Nishimura T. Technetium99m HL91 uptake as a tumour hypoxia marker: relationship to tumour blood flow. Eur J Nucl Med 1999;26:91-4.

127. Kinuya S, Yokoyama K, Konishi S, Li XF, Watanabe N, Shuke $\mathrm{N}$, et al. Increased uptake of $99 \mathrm{mTc}-\mathrm{HL} 91$ in tumor cells exposed to X-ray radiation. Ann Nucl Med 2000;14:139-41.

128. Siim BG, Laux WT, Rutland MD, Palmer BN, Wilson WR. Scintigraphic imaging of the hypoxia marker $(99 \mathrm{~m})$ technetiumlabeled 2,2'-(1,4-diaminobutane)bis(2-methyl-3-butanone) dioxime (99mTc-labeled HL-91; prognox): noninvasive detection of tumor response to the antivascular agent 5,6-dimethylxanthenone-4-acetic acid. Cancer Res 2000;60:4582-88.

129. Suzuki T, Nakamura K, Kawase T, Kubo A. Biodistribution of hypoxic marker, 99mTc-HL91 (4,9-diaza-3,3,10,10-tetramethyldodecan-2,11-dione dioxime) [in Japanese]. Kaku Igaku 2001;38:333-41.

130. Suzuki T, Nakamura K, Kawase T, Kubo A. Monitoring of response to radiation therapy for human tumor xenografts using 99mTc-HL91 (4,9-diaza-3,3,10,10-tetramethyldodecan-2,11dione dioxime). Ann Nucl Med 2003;17:131-8.

131. Kinuya S, Yokoyama K, Li XF, Bai J, Watanabe N, Shuke N, et al. Hypoxia-induced alteration of tracer accumulation in cultured cancer cells and xenografts in mice: implications for pretherapeutic prediction of treatment outcomes with $(99 \mathrm{~m}) \mathrm{Tc}-$ sestamibi, (201)Tl chloride and (99m)Tc-HL91. Eur J Nucl Med Mol Imaging 2002;29:1006-11.

132. Lee BF, Chiu NT, Hsia CC, Shen LH. Accumulation of Tc- $99 \mathrm{~m}$ HL91 in tumor hypoxia: in vitro cell culture and in vivo tumor model. Kaohsiung J Med Sci 2008;24:461-72.

133. Cook GJR, Houston S, Barrington SF, Fogelman I. Technetium99m-labeled HL91 to identify tumor hypoxia: correlation with fluorine-18-FDG. J Nucl Med 1998;39:99-103.

134. Van De Wiele C, Versijpt J, Dierckx RA, Moerman M, Lemmerling M, D'Asseler Y, et al. 99Tc(m) labelled HL91 versus computed tomography and biopsy for the visualization of tumour recurrence of squamous head and neck carcinoma. Nucl Med Commun 2001;22:269-75.

135. Li L, Yu J, Xing L, Ma F, Zhu H, Guo H, et al. Serial hypoxia imaging with 99mTc-HL91 SPECT to predict radiotherapy response in nonsmall cell lung cancer. Am J Clin Oncol 2006;29:628-33. 